\title{
"EL LLENGUATGE HA POSSEÏT EL COS". CAP A UNA ANTOLOGIA DE LES POETES CATALANES DEL S. XXI
}

Ens cal una altra antologia de poetes? Ens podem preguntar si queda poesia per descobrir després de la publicació de nombrosos reculls com Paisatge emergent: Trenta poetes catalanes del segle XX (2000), Donzelles de l'any 2000 (2013), Com elles: Una antologia de poetes occidentals del segle XX (2017); de caire més general, com Mig segle de poesia catalana: Del maig del 68 al 2018 (2018), o específic, amb Amors sense casa. Poesia LGBTQ catalana (2018). La resposta és aquesta proposta que sí veu necessari mostrar un moment poètic molt concret, prolífic, eclèctic, i possiblement efímer. El desafiament que motiva aquesta selecció és la tasca d'escollir la tria més representativa, diversa i de qualitat possible, en la interacció de la poesia escrita per dones en català amb un fort component corporal i la consideració temporal, perquè totes les autores incloses han publicat el seu primer llibre a partir del 2010. Catalogar, limitar, la producció a l'última dècada del segle XXI, un període que encara s'està escrivint i una època celebrada per la crítica perquè s'hi "viu una glopada d'aire fresc, de permeabilitat i d'heterogeneïtat que no passa desapercebuda [...] [i que] significa l'aparició de noves autories amb veu pròpia que segueixen tradicions fins llavors alienes al cànon tradicional” (Madueño, 2019). Estem davant d'una tasca impossible?

Parlava d'interseccions i posava com a punt de partida el 2010, però la poesia d'aquesta dècada no es pot entendre sense mirar una mica enrere, concretament cap al 2006, amb Poètiques del cos, de Mireia Calafell. Significatiu perquè ens mostra un moviment a les lletres sobretot - tot i que no únicament- escrites per les dones, on destaca un interès comú per la corporalitat, la sexualitat i el trencament dels tabús que hi van relacionats. Un propòsit, d'explorar la intimitat com a motor poètic, que s'anirà repetint en les autores que publicaran després d'aquesta data: "El repte és també recuperar el cos a través de la paraula i fer-ho de manera que se superi la paradoxa d'anomenar-lo sense fixar-lo. ¿Com dir el cos sense perdre'n la capacitat productiva en tant que procés?" (Calafell, 2011: 84). Els poemes d'aquesta autora, que el 2010 seguiria amb Costures, són la llavor i l'adob d'un sòl que ja era fèrtil i que esclata amb nombroses veus noves, que ara ja són noms consolidats. 
Per exemple, el debut de Maria Cabrera, Jonàs, va ser el 2004, el primer llibre de Maria Antònia Massanet, Disseccions emocionals, també és del 2006 i Anna Gual s'estrenà amb Implosions el 2008. Tornant a la dècada que ens ocupa, destaquen dos anys per sobre de tot: el 2015, amb la publicació dels primers llibres de Maria Sevilla i Raquel Santanera; i el 2017, que va ser un any especialment prolífic, amb el segon llibre d'aquestes poetes i amb les estrenes de Maria Isern, Anna Gas, Núria Armengol, i Helga Simon - ja observava Francesco Ardolino que els autors novells (i les autores sobretot) en "els darrers tres o quatre anys s'han multiplicat i consolidat a una velocitat sorprenent” (2017: 50). És el decenni, també, de la confirmació de Lucia Pietrelli i de Glòria Coll. I a més, és el gran moment de l'aposta de les editorials per la poesia, la renovació de l'Horiginal, els dilluns de poesia al $\mathrm{CCCB}$, i la bona salut de la Setmana de la Poesia de Barcelona o del Festival Nacional de Poesia a Sant Cugat, només per esmentar alguns fets paral.lels a aquestes publicacions.

\section{"Soc algú —una dona- que escriu"}

Si parafrasegem Maria-Mercè Marçal, de seguida vindrà a llum l'altre motiu d'aquesta antologia: unes autores que converteixen la seva veu de dones en l'eina primària de la seva reflexió i revolta mitjançant allò més íntim, que no deixa de ser "la representació dels impulsos primaris, d'allò amenaçador, desconegut, identificat amb el mal i que, per tant, la civilització defuig i condemna" (Marçal a Julià, 2018: 43). Hi reflexiona també Lluís Calvo: "Del feminisme a la identitat mutant i flexible, tot passant per la crítica corrosiva de la figura masculina i el relleu atorgat al cos, la jove poesia ha obert noves sendes de denúncia i afirmació” (2016: 65). Es recupera així, si mai s'havia abandonat, la vella fórmula segons la qual el personal és polític, amb uns versos que aglutinen la carnalitat més ferotge i els pensaments més prominents sobre el gènere de la tradició filosòfica del segle $\mathrm{XX}$, amb una forta càrrega teòrica on el cànon el formen noms com Judith Butler, Donna Haraway, Virginie Despentes o Rosi Braidotti. Relacionar les teories de gènere amb les experimentacions pròpies de les autores donarà un resultat comú: la posició combativa que aquestes acaben ocupant davant dels rols tradicionals. En una societat asèptica on el dolor o la brutor s'oculta i molesta, la resposta sorgeix en aquests versos que en reivindiquen la memòria, el dret a no amagar. La nafra ocupa un lloc primordial, la cicatriu es fa paraula, l'abjecte qüestiona els discursos apresos i explicita la inestabilitat dels tabús, com la sang menstrual o la sexualitat femenina. Ni tan sols un material llis com el marbre s'escaparà de les imperfeccions de les veus poètiques, que posen un punt i final a la distinció entre interior i exterior exposant els límits del cos, els teixits i la sang que s'alcen contra la contenció (auto)imposada. La pell guanya pes per a percebre el món i aglutina significats per a construir el subjecte i els altres, i, com a tal, s'escriu clivellada i foradada desestabilitzant les 
identitats. Diguem-ho amb Mireia Calafell: "s'escriu al límit de l'ésser com a l'altre, a la frontera d'allò que som, el que fórem i el que serem. [...] [En] el territori del text i del cos, que és sempre la zona en què apareix l'altre que configura la nostra identitat per fer-nos més i menys vulnerables alhora, escriure on no sabem" (2011: 85). El jo inacabat ens connecta amb els altres i d'aquí en surt la vulnerabilitat, un concepte que aquestes poetes aborden des de nombroses perspectives.

La força política es transmet amb la transformació de les muses en fúries. El cos permet articular el crit d'aquests éssers mitològics — dels quals Marçal ja n'intuiia la força creadora- condemnats als esgarips, però sense escriure amb ira, sinó amb la pell. Una proposta que esdevé un fet constant amb aquests versos caracteritzats per "la afirmación del goce femenino, la apropiación del lenguaje, la vulneración de los tabúes y las convenciones morales, y la creación de nuevas representaciones femeninas en el imaginario literario y cultural" (González Fernández, 2009: 89). La subversió que suposa la sexualitat femenina s'accentua situant la dona com a subjecte desitjant, donant pas a la recerca de noves possibilitats de representació, sense que això n'impliqui una centralitat absoluta o mancada de contradiccions: "sobre todo a partir de las teorías feministas, el deseo femenino deja de ser sólo un objeto de fascinación y de representación para pasar a ser 'sujeto de acción”" (Segarra, 2007: 11). Aquesta definició és cabdal per moure la mirada patriarcal i per entendre aquestes poetes, que molts cops oscilllen de la reflexió lírica als articles, dels recitals a l'activisme social. Tot plegat pot comportar el risc de caure en el pamfletisme, tant d'autores com de crítica, la qual també pot caure al parany. El qüestionament de la figura femenina - i de retruc masculina- a través del cos, també vehicula les preguntes sobre la performativitat del gènere, que exhibeix la mascarada d'actuar segons els models previstos. Elles hi escriuen a la contra per rebel-lar-se contra els patrons heretats i transmesos. Així, ens trobem davant d'uns poemes amb qüestions sexuals explícites, manifestament fora de la "faula carrinclona" i "la lliçó moral qui sap si producte d'una evolució imitativa o social", amb un discurs de "revalorització del cos i del plaer" (Florit, 2018: 40) centralment femení, hi podem afegir.

No vull obviar, tot i que sempre acaben mancant noms, els altres referents que han conduït fins aquí, ja que la poesia no deixa de ser sempre també un diàleg. Destaquen com a més citades: Maria-Mercè Marçal, Rosa Leveroni, Alejandra Pizarnik, Anne Sexton o Sylvia Plath. I, amb elles, Gabriel Ferrater, Blai Bonet, Enric Casasses i Joan Vinyoli. Aquesta proposta se centra en l'inici del camí, amb unes autores escollides per la seva qualitat i perquè són - semblen- les millors representants d'aquest moment poètic. Tanmateix, la mirada que comença amb elles ens porta al futur: aquest recull és una aposta per unes veus que poden ser cabdals per la poesia catalana i que s'han de seguir de ben a prop. És per això que l'èmfasi 
recau en l'estat en construcció d'aquesta antologia on el llenguatge ha posseït el cos i el cos, la poesia. Al límit de la pell, s'escriu la metàfora.

MeritXell Matas

Universitat de Barcelona

\section{REFERÈNCIES BIBLIOGRÀFIQUES}

Ardolino, Francesco (2017), "Balanç poètic 2017. Aires de colònia. Concert a quatre veus acompanyades per un triangle", Jocs Florals de Barcelona 2018, Barcelona, Ajuntament de Barcelona: 45-63.

Calafell, Mireia (2011), “Entre les paraules i les coses, allà on la poesia s'aboca per a donar(-te) cos”, Noemí Acedo i Aina Pérez (eds.), A flor de text. Representacions de la corporeïtat als llenguatges artístics, Barcelona, Editorial UOC: 7786.

Calvo, Lluís (2016), “Audaces i talentoses: La jove poesia a l'inici del segle XxI”, Àlex Broch i Joan Cornudella (eds.), Poesia catalana avui 2000-2015, Juneda, Fonoll: 47-148.

Florit Robust, Jordi (2018), "La poesia de l'experiència. L'única experiència possible?”, La poesia catalana al segle XXI. Balanç crític, Olívia Gasol i Òscar Bagur (eds.), Barcelona, Societat catalana de llengua i literatura: 27-48.

González Fernández, Helena (2009), Género y nación. La construcción de un espacio literario, Barcelona, Icaria.

Julià, Lluïsa (2018), "La poesia, la sang i el drac. Glossa de Maria-Mercè Marçal”, Jocs Florals de Barcelona 2018, Barcelona, Ajuntament de Barcelona: 41-43.

Madueño Sentís, David (2019), "Del Silici al Mercuri. Poesia catalana actual”, Quadern de les idees, les arts $i$ les lletres, 216. <https://www.quadern216funda cioars.org/blog/del-silici-al-mercuri-poesia-catalanaactual-1a-part-viure-a-la -intemperie>

Segarra, Marta (2007), Políticas del deseo, Barcelona, Icaria. 